\title{
A Case Study: Using The Wearable Computer In The Construction Industry
}

\author{
by
}

\author{
Scott Fuller, Zhihui Ding, and Anoop Sattineni
}

\begin{abstract}
This paper aims to explore the prospective applications of cuttingedge technology like wearable computers in construction industry. The history, current research, application areas and future trends of wearable computing are investigated. The first-hand experience of the authors through a well-designed field experiment is introduced in detail to show how the technologies actually work. The field experiment is performed using three different methods, including by hand, by Palm PC and by wearable computer. The pros and cons for each are analyzed and compared to reveal why wearable computer is a better tool to help construction professionals to perform their daily duties like "punch-list". The results in summary showed that in immediate future, wearable computer is a better solution for construction than Palm PCs. But the advocates of the wearable computer should always bear in mind that the technologies are always developing. Palm PCs are still expanding their functionality while maintaining the mobility. It is not impossible that tomorrow they could have the same storage and processing capacities as wearable computers today. So Palm PCs are going to be strong competitors of wearable computer.
\end{abstract}

KEYWORDS: Construction, Palm PC, Punch List, Wearable Computers

\section{INTRODUCTION:}

The construction industry is on the edge of something that could drastically improve the entire construction process. Recently, a new kind of computer has caught the public attention, a 'wearable computer': a computer that can be worn on a human body. Its mobility and functionality has made it useful in many places where a regular computer could not be carried. This "...has the ability to bridge time/distance constraints imposed by working at remote construction projects...the opportunity for real-time decision making in construction is improved." 1

\section{LITERATURE REVIEW}

Through the extensive research, the authors found the term "wearable computer" has been defined in several ways. For example, according to MIT wearable computing lab, wearable computer is a computer that should be worn much as "eyeglasses or clothing", and interact with the user based on the context of

\footnotetext{
${ }^{1}$ Mills and Beliveau, 1998
}

the situation. With features like heads-up displays, unobtrusive input devices, and personal wireless local area networks, the wearable computer can act as an intelligent assistant. NASA (National Aeronautics and Space Administration) used the term Body Wearable Computer (BWC), which is a battery-powered computer system worn on the user's body. And the unit is designed for mobile and predominantly hands-free operations, often incorporating head-mounted displays and speech input. ${ }^{2}$

Today, there are a lot of commercial wearable computing systems available in the market. Some prototypes require special glasses, while others rely on sensors similar to medical electrodes on various body parts to feed data to the computer. The differences depend on the purpose of each system. Among all systems, Xybernaut Corporation is one of the largest sellers, partly because it has locked up a big

${ }^{2}$ Auburn University, Department of Building Science, 119 Dudley Hall, Auburn, Alabama 36849, 334-844-5431, fulleds@auburn.edu Mizrachi, 2000 
chunk of the patents. ${ }^{3}$ Figure 1 shows Mobile Assistant V, one member of Xybernaut wearable computer family.

In summary, wearable computers are more powerful, durable than laptop/palm computers, but more convenient to use than desktop PCs. ${ }^{4}$ As Ed Newman, chairman and CEO of Xybernaut, said, "We're not talking about a Windows CE device; we're not talking about a PDA, we're talking about a product that literally will run anything your laptop or desktop will run with almost no change." Wearable computers are able to run "all the programs on a PC", including word processing, spreadsheets, and databases, but in a more efficient way. ${ }^{5}$

Today, wearable computers are not stagnating at the laboratory and exotic-toy stage. ${ }^{6}$ Instead, they are finding wide use in the real world. For Xybernaut alone, its current customers include many companies that have large field forces, such as FedEx Corp., Bell Canada, and the U.S. Army and Navy, to name a few. ${ }^{7}$

FIATECH, a research and development firm, has a two-year goal to introduce wearable computers to the construction industry. FIATECH will record the activities of people in the field to understand how their work is done and how it can best be improved through the use of a wearable computer. ${ }^{8}$

One of the major issues with the construction industry is that the production activity is dispersed and the site locations frequently change. This is a disadvantage for the construction industry that most other industries do not have. This makes IT support and integration for the construction industry more difficult. ${ }^{9}$ This in turn makes it a great candidate for the wearable computer or mobile computing. In addition, effective communications is the most important

$$
\begin{array}{r}
{ }^{3} \text { Maney, } 2001 \\
{ }^{4} \text { Merritt, } 2001 \\
{ }^{5} \text { Mizrachi, 2000 } \\
{ }^{6} \text { Mizrachi, } 2000 \\
{ }^{7} \text { Neel, } 2000 \\
{ }^{9} \text { Rebolj, Magdic, and Cus-Babic, } 20000
\end{array}
$$

component for successful projects. Communication between the participants on a job site is difficult, due to the large number of participants, their remote locations, the visual nature of many issues/solutions, the number of problems that arise at the site and the need for them to be solved on-site. However, it is also exactly these kinds of issues that might make the wearable computer a very effective, efficient, useful and beneficial tool for construction. $^{10}$

Certainly for the construction industry the wearable computers and all attached devices must be accessible, lightweight, and easy to use. They must be able to withstand all types of weather and environmental conditions. For example, the screen should be readable in all types of lighting, the computer should be impact resistant, have rechargeable batteries and a host of other functions and ergonomic features. ${ }^{11}$

${ }^{12}$ Mills and Beliveau proposed the idea of "Virtual Site Visit" using wearable computers. A "Virtual Visit" is a visit to a construction site to observe, evaluate, clarify and correct actions and activities, but it occurs without the individual's actual physical presence. This is of great benefit when it is impossible to visit the site and will diminish project delays. The reduction in travel time and increased project knowledge translates into immediate cost savings to the contractor, owner and designer.

Just as Jim Porter, with Dupont says, "In today's competitive environment, we need to be able to access data, drawings, and other information on demand remotely at the construction site. Wearable computers will allow us to do this." 13

Essential to using advanced computing technology for field decision making is an understanding of the jobsite informational needs. Research on using wireless communications for construction information

\footnotetext{
${ }^{10}$ Miah, et al, 1998

${ }^{11}$ Newland and Owings, 2001

${ }^{12}$ Mills and Beliveau, 1998

${ }^{13}$ Newland and Owings, 2001
} 
needs has been undertaken and reported by the Construction Industry Institute. ${ }^{14}$

Two of the authors conducted a preliminary survey with some construction firms. The purpose of the survey was to investigate the potential uses for the wearable computer technology and the interest in the industry.

The survey indicated that the construction industry is already using information technology to improve performance on projects. It also showed that an enormous amount of data is recorded on the job site by construction personnel. All respondents indicated that they would be willing to experiment with wearable computer technology, thus indicating that there is a tremendous potential for the success of wearable computer technology.

\section{METHODOLOGY}

The objective of this research project is to test the wearable computer in a real-life situation in construction to see how technology could help construction professionals. For example, compare the different time periods required to perform the same amount of work, under different methods including by hand, by Palm $\mathrm{PC}$ or by wearable computer.

In order to do so, first the author should have a wearable computer system configured and use it extensively to get to know it well. Secondly, the author should identify a testing area where experiments with such appropriate scale could be performed to "mock" the real-life situation. Lastly, putting the two aspects together, the author should design a testing scheme and further configure the wearable computer system for the testing purpose.

The wearable computer used in research will come from Department of Building Science, Auburn University. This Xynernaut computer, the Mobile Assistant V (MA V), will contain a $500-\mathrm{MHz}$ Intel Celeron processor, 128-MB of RAM, and a 2-GB hard drive that can be worn in a vest or on a belt. It will be able to run all major PC operating systems, including Windows 2000/NT and Linux. The MA V will also incorporate a daylight-viewable, headmounted display or a wrist-mounted SVGA flat panel touch-screen viewable in all light levels. Interaction with the computer will be made via a wrist-worn keyboard, touch-screen, or voice recognition software.

The following lists three ways that we proposed to test the wearable computer for construction applications: 1. Traditional Manual Method, 2. Palm-size PC, 3. Wearable computer.

In our testing, the actual situation might vary from the above. However, at least, the following conditions must be met, before performing research related to punch list: a building should be identified and available for research purpose; drawings (traditional blueprints or electronic format), specifications (or scope statement) should be made available; the author should develop sample checklist and punch list for field use; technical tools, such as Palm-Size PC, wearable computers, should be well-configured before hand; and bring some accessories, like stop watch to record time, pens and paper.

\section{RESULTS}

\subsection{Field Testing}

The author selected Intramural Fieldhouse at Auburn University as the target building for carrying out the "Punch-list" experiment. Based on the information from drawings and specifications, a sample checklist and punchlist were first developed in MS Excel spreadsheet and Word document format, respectively. Then three trips were made separately to perform the building inspection, by hand, by Palm PC and by wearable computer. Plumbing and electrical systems were the primary emphases, but interior finishes and furniture were also included. The process is defined as from the time when the author entered the building to the time when the checklist and punch list were completed. 
From the experience in performing the "punchlist", the author summarized the pros and cons for each method, as in Table 1.

Firstly, the advantage for using mobile computing device over manual method is quite apparent. Whether using Palm PC or wearable computer, when the punch list is done, it will be sent through e-mail instantly. But with the manual method, the superintendent will have to come back, find a desktop PC, and manually put all information into a computerized system (or scan in the paper form) to be sent via email to subcontractors at the same day.

If we assume the distance between the jobsite and home office is two miles, the additional travel time and data input time, in our case, will be approximately 20 minutes. In real life, the travel time will be even significantly longer. So if assuming the added time for communicating the punch list to subcontractors is one hour under the manual method, the above timetable should be adjusted as Table 2 indicates. Now one could see clearly that using computerized methods, the problem of "double data entry" and delivery time could be eliminated, thus significantly improving the efficiency.

In our experiment, the electronic drawings are around $20 \mathrm{MB}$ in total. This was not a big issue for our wearable computer, which has two hard drives (2 GB in total storage capacity). But it was a huge burden for our Palm PC, which only has $8 \mathrm{MB}$ storage. So our experiment reveals that wearable computer did outperform Palm PCs in storage capacity, with or without external devices.

\subsection{Data Access}

With wearable computer, the electronic drawings were loaded as well as electronic version of checklist and punch-list, all that the author needed to do is to carry the wearable computer around. It should be noted that in our experiment, the idea of electronic drawings didn't apply to the manual method or Palm PC at all. That is because Palm PCs do not have the power to manipulate electronic drawings. Even within the near future, this situation is not very likely to change, considering the fact that the drawing viewing tool itself alone will take more than $4 \mathrm{MB}$ and doesn't work with Palm PC at all.

\subsection{Data Processing}

Wearable computers don't require special applications loaded in order to process data. But Palm PCs will require special software to perform the same tasks., like Pocket Microsoft Office (Pocket Word, Pocket Excel, Pocket Access etc). This software costs the same price, if not more, as the standard software does. In addition, some features in regular applications will be unavailable in the software designed for Palm PCs. In this experiment, the authors was able to add a password-protected digital signature to the punch list when using wearable computer. But using Palm PC, the document was converted to Word Pad text file, and all macros were lost. In addition, the software installation process is also more complicated for Palm

\subsection{Data Synchronization}

An important issue for mobile computing devices is how the data on them could be communicated back and forth into the current corporate network, which is almost exclusively based on a group of desktop workstations. Although our experiment finished when punch lists were complete, in real life, all data on wearable computer or Palm PC must be finally backed up and updated. E-mail is fine for exchanging small files like the punch list as a Microsoft Word document in our experiment. But for larger files, other solutions must be sought.

For Palm PC, as described earlier, this relies on the communication between Palm PC and a desktop PC. First prepare desktop PC for synchronization purpose by installing special utility software like Microsoft ActiveSync on it. Then connect Palm PC with desktop PC by using a cable. Activate Microsoft ActiveSync or other similar program, and the data between the two will be exchanged or updated. Except for the first time, which requires software 
installation, all one has to do is connect the cable and click the button.

In our experiment, the solution for wearable computer was "Sneak Net", i.e. transporting data via 3-1/2" floppy-disks with the help of related USB devices. But even by that, wearable computers still outperform Palms in this aspect, because the USB devices are basically mechanical operated (Plug-PlayUnplug) and easy to bring with wearable computers.

From the discussion above, it seems that within the near future, wearable computer is a better solution for construction than Palm PCs. But the advocates of wearable computer should always bear in mind that the technologies are always developing. Palm PCs are still expanding their functionality while maintaining the mobility. It is not impossible that tomorrow they could have the same storage and processing capacities as wearable computers today. So Palm PCs are going to be strong competitors of wearable computer.

\section{CONCLUSIONS:}

For wearable computers, a lot of things could be done. Especially, one should look at the strengths of Palm PCs to improve the performance. For example, wearable computers could be made smaller in size, easier to carry, having lighter CPU or even integrating CPU with monitor into one unit etc.

In our experiment, the punch list and checklist files were first edited in a desktop computer, and then saved to a floppy disk to be later transferred to wearable computer. This is the "Sneak Net" process we talked about earlier. But in construction, the needs for data updates between office and field could be very frequent and heavy. Thus the data synchronization process described above could be so labor intensive and time consuming for anyone.

Ideally, the wearable computer will be a workstation ("Client") in the corporate clientserver networking environment. Just like a normal desktop PC, a wearable computer could download file from, and also upload files to, the company server. It will have Internet access via the corporate server. Considering the diverse nature of the construction industry, the wearable computers could be configured into wireless communication mode. The limitations for current wireless technology could be overcome by setting up a small-scale LAN in each jobsite, where the local server in the trailer could directly meet the needs of mobile devices by communicating the company server. However, the costs for establishing such networks and maintaining them could be so prohibitively expensive for any contractor. Some recent innovations in IT industry like ASP (Application Service Provider) might provide better solutions to such problem.

In addition to the issues discussed above, some technologies that are supposed to work with wearable computers, like speech recognition and head-mount display, are far from mature to be applied in construction industry in a significant scale.

In summary, the application of wearable computers in construction industry could offer improved efficiency. But the future researchers and developers should improve the performance and practicability of the technology before it is widely accepted by construction industry professionals.

\section{REFERENCES:}

De la Garza, Jesus M., Howitt, Ivan. Wireless Communication and Computing at the Construction Jobsite. Construction Industry Institute Research Summary 136-1, 1997.

Maney, K. (2001, April 18). Wearable PCs: $A$ different kind of fashion statement [WWW document]. URL http://www.usatoday.com/life/cyber/tech/revie w/2001-04-18-wearable.htm

Merritt, R. (2001). Switching fabric. Electronic Engineering Times, 1191, 1-3

Miah, T., Carter, C., Thorpe, A., Baldwing, A., and Ashby, S. (1998). Wearable computersan application of BT's mobile video system for 
the construction industry. BT Technol Journal, Vol. 16, No. 1, pp 191-199.

Mills, T., and Beliveau, Y. (1998). Virtual Site Visit Using Wearable Computers. The 1998 International Conference on Wearable Computing, Fairfax, VA, 1998.

Mizrachi, D (2000) Info-Fashions for the New Millennium, Online, 24(1), 82-85

Neel, D (2000) Wearable PC goes to work, InfoWorld, 22(47), 10

Newland, B., and Owings, C. (2001, Jan. 9). In the field, wearable computers will change how work is done. [WWW document]. URL http://www.djc.com/news/co/11127075.html

Rebolj, B., Magdic, A., and Cus-Babic, N. (2000, Jan 9). "Mobile Computing in Construction". [WWW document]. URL

http://kamen.uni-mb.si/cgi/Mobile \%20computing\%20in\%20construction.htm

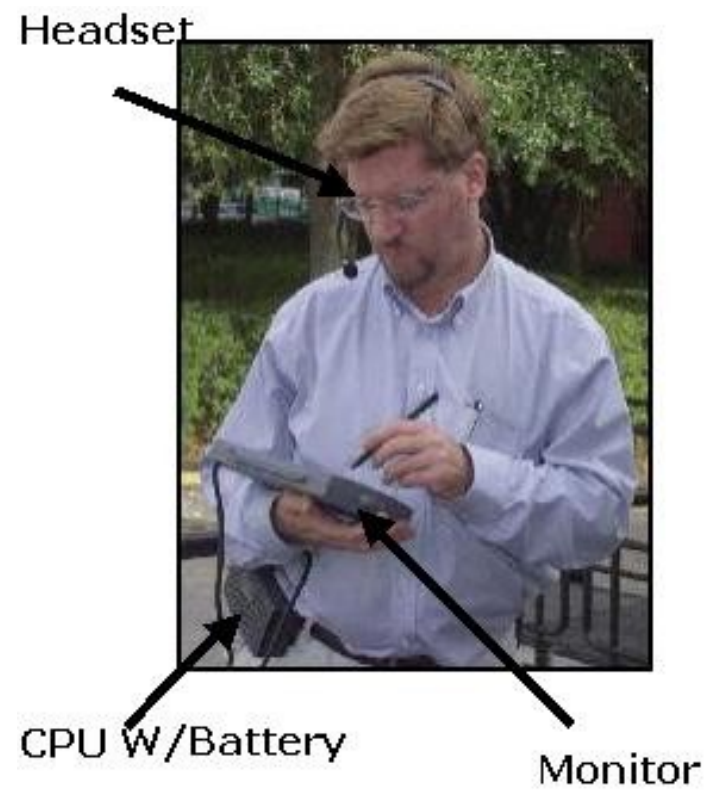

Table 1.

Comparison of Three Different Methods

Table 2.

Adjusted Results due to communication time.

\begin{tabular}{lcc}
\hline \multicolumn{1}{c}{ Method } & $\begin{array}{c}\text { Original } \\
\text { Time }\end{array}$ & $\begin{array}{c}\text { Adjusted } \\
\text { Time }\end{array}$ \\
\hline Manual & 76 Minutes & 136 Minutes \\
Palm PC & 95 Minutes & 95 Minutes \\
Wearable & 66 Minutes & 66 Minutes
\end{tabular}

Figure 1: MA V Wearable Computer by Xybernaut Corporation.

\begin{tabular}{llll}
\hline Method & Advantages & Disadvantages & Human Factor \\
\hline Manual & $\begin{array}{l}\text { Quick and easy to input } \\
\text { data }\end{array}$ & $\begin{array}{l}\text { Hard to manipulate blueprints and } \\
\text { writing pad simultaneously }\end{array}$ & $\begin{array}{l}\text { Fatigue in wrist and arms } \\
\text { and sweating body }\end{array}$ \\
Palm PC & $\begin{array}{l}\text { No need for paper forms, } \\
\text { Palms easy to carry, light } \\
\text { weight }\end{array}$ & $\begin{array}{l}\text { Still require blueprints, screen hard } \\
\text { to read where not much lights, } \\
\text { slower input }\end{array}$ & Eye fatigue \\
Wearable & $\begin{array}{l}\text { No need for blueprints or } \\
\text { paper forms, instant access } \\
\text { to everything from } \\
\text { anywhere }\end{array}$ & $\begin{array}{l}\text { Require time to put up parts on } \\
\text { body, and wait for the system to } \\
\text { boot up; Require operations to } \\
\text { drawings like zooming in and out, } \\
\text { moving up and down }\end{array}$ & $\begin{array}{l}\text { Finger fatigue after } \\
\text { continuous data input using } \\
\text { arm-worn keyboard }\end{array}$ \\
\end{tabular}

